\title{
Diving Into Diagnostic Uncertainty: Strategies to Mitigate Cognitive Load: In Reference to: "Focused Ethnography of Diagnosis in Academic Medical Centers"
}

\author{
Lekshmi Santhosh, MD*, Katie Raffel, MD, Sumant R. Ranji, MD
}

University of California-San Francisco, San Francisco, California.

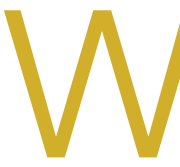

e read the article by Chopra et al. "Focused Ethnography of Diagnosis in Academic Medical Centers" with great interest. ${ }^{1}$ This ethnographic study provided valuable insights into possible interventions to encourage diagnostic thinking.

Duty hour regulations and the resulting increase in handoffs have shifted the social experience of diagnosis from one that occurs within teams to one that often occurs between teams during handoffs between providers. ${ }^{2}$ While the article highlighted barriers to diagnosis, including distractions and time pressure, it did not explicitly discuss cognitive load theory. Cognitive load theory is an educational framework that has been described by Young et al. ${ }^{3}$ to improve instructions in the handoff process. These investigators showed how progressively experienced learners retain more information when using a

*Address for correspondence: Lekshmi Santhosh, MD; University of California-San Francisco, Department of Medicine, Divisions of Hospital Medicine \& Pulmonary and Critical Care Medicine, 505 Parnassus Avenue, San Francisco, CA 94143; E-mail: Lekshmi.Santhosh@ucsf.edu

Received: May 30, 2018; Accepted: July 19, 2018

(c) 2018 Society of Hospital Medicine DOI 10.12788/jhm.3077 structured scaffold or framework for information, such as the IPASS mnemonic, ${ }^{4}$ for example.

To mitigate the effects of distraction on the transfer of information, especially in cases with high diagnostic uncertainty, cognitive load must be explicitly considered. A structured framework for communication about diagnostic uncertainty informed by cognitive load theory would be a novel innovation that would help not only graduate medical education but could also improve diagnostic accuracy.

Disclosures: The authors have no conflicts of interest to disclose

\section{References}

1. Chopra V, Harrod M, Winter S, et al. Focused Ethnography of Diagnosis in Academic Medical Centers. J Hosp Med. 2018;13(10):668-672. doi: 10.12788/ jhm.2966.

2. Duong JA, Jensen TP, Morduchowicz, S, Mourad M, Harrison JD, Ranji SR. Exploring physician perspectives of residency holdover handoffs: a qualitative study to understand an increasingly important type of handoff. J Gen Intern Med. 2017;32(6):654-659. doi: 10.1007/s11606-017-4009-y

3. Young JQ, ten Cate O, O'Sullivan PS, Irby DM. Unpacking the complexity of patient handoffs through the lens of cognitive load theory. Teach Learn Med. 2016;28(1):88-96. doi: 10.1080/10401334.2015.1107491.

4. Starmer AJ, Spector ND, Srivastava R, et al. Changes in medical errors after implementation of a handoff program. N Engl J Med. 2014;371(19):18031812. doi: $10.1056 / N E J M c 1414788$. 